\title{
Calls for a better food guide
}

I t promotes overconsumption. It's too soft on highly refined carbohydrates. It considers sugary juices equivalent to fruit. It doesn't reflect what Canadians actually consider a serving size. It's influenced by the food industry. It doesn't differentiate between good and poor sources of proteins and fats. It's outdated, too general and not all that useful.

Let's hope Canada's Food Guide isn't overly sensitive to criticism, because these are but a sampling of the complaints lobbed its way in recent years.

"It's kind of overdue for a change," says Dr. Javed Alloo, a family physician in Toronto with a practice focus on diabetes.

The biggest problem with the food guide, however, may not be about content, says Alloo, who seconded a motion to advocate for a revision at the Canadian Medical Association's recent annual general council. Relevancy is the larger issue. The philosophy behind the food guide is old-fashioned, he says, and it has resulted in an antiquated document designed merely to exist rather than to actually invoke change.

"When you look at changing a food guide, the point is not to make another set of rules and lists, which is still useful information and necessary, but how to actually make it meaningful. Making the food guide have a bigger impact than it actually does now is part of what a revision would need to include," says Alloo. "You have to figure out how to increase adoption rather than just create another good-looking guide."

That would mean focusing on endusers and meeting their needs, says Alloo. To create a more effective tool, one that will help people better self-regulate their diets to improve health, the public needs to be engaged earlier in its creation. A more useful food guide is one that provides tools to personalize information for different subgroups, such as people with diabetes or those with a family history of heart disease. It should contain practical and nuanced

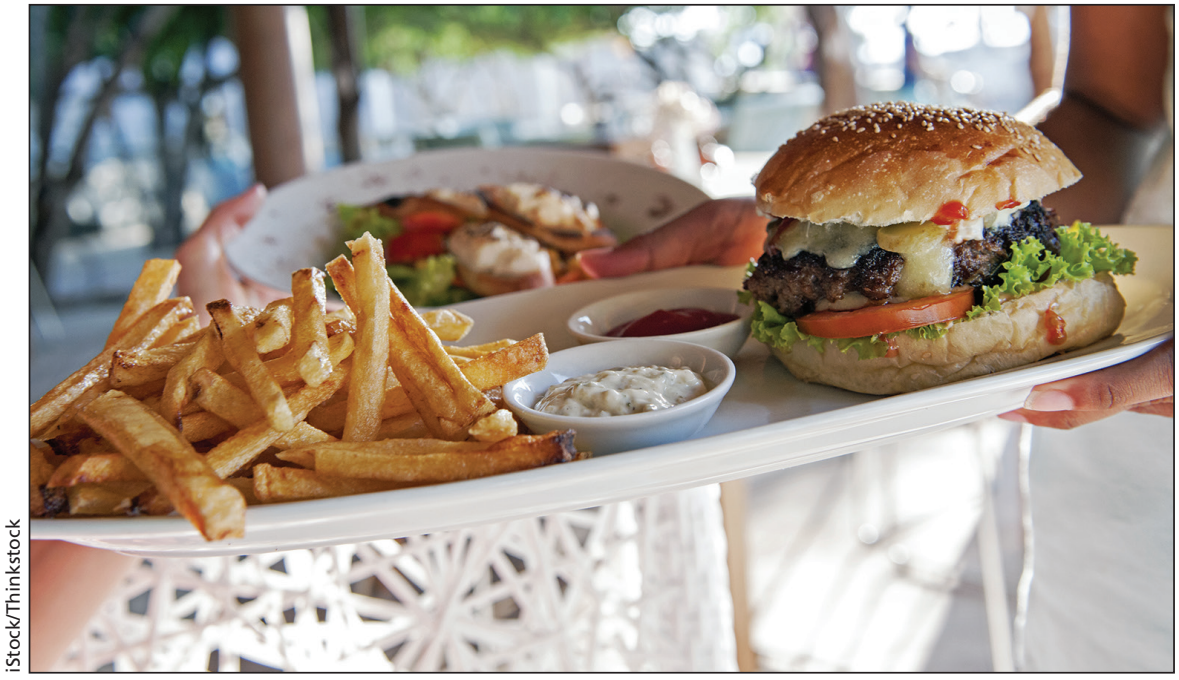

One criticism of Canada's Food Guide: It does not accurately reflect what Canadians actually consider a serving size.

information on topics such as food security and social determinants of health.

If Canada's Food Guide doesn't evolve and become more useful to the public, it risks becoming a relic. For some health care providers, says Alloo, the guide is already fast approaching irrelevancy.

"How often do we actually refer to it? Not much. We use common sense," says Alloo. "And we understand context far better than the guide ever did."

Other factors that should be considered in updating the food guide include adding emerging research on diet and nutrition, changes in consumer behaviour and changes to the food supply, says Kate Comeau, a spokesperson for Dietitians of Canada.

"No guide is ever going to suit everybody's needs, but there is a need to continuously update it and make sure that it's as effective as it can be," says Comeau.

Health Canada says it is working to ensure the food guide is "scientifically sound, relevant and useful." Though the guide hasn't been revised since 2007, the agency recently implemented an "evidence review cycle" to allow for regular investigation of the evidence supporting the document.

"As scientific knowledge evolves and
Canadians continue to adapt to their changing environments, Health Canada will continue to provide appropriately updated and relevant guidance for Canadians," states an email sent by Gary Holub, a media relations officer at Health Canada.

If Health Canada does eventually revise the food guide again, it will have to improve it quite a bit more than last time to please one of its more outspoken critics. Dr. Yoni Freedhoff, an expert on obesity and medical director of the Bariatric Medical Institute in Ottawa, gave the 2007 version a grade of $\mathrm{C}+$ on his blog Weighty Matters. The big winners of the revision were the beef and dairy industries, he wrote, not the Canadian public.

In other blog posts, Freedhoff has described the guide as obesogenic, relabelled it as "Canada's Food Guide to Unhealthy Eating" and said that, bottom line, it "stinks." That's unfortunate, he wrote, because even if most Canadians don't stick the food guide on their fridges, it is still important: "It permeates our nutritional consciousness and becomes the nutritional backdrop of our society." - Roger Collier, CMAJ

CMAJ 2014. DOI:10.1503/cmaj.109-491 